\title{
Simulation on the plunge stage in refill friction stir spot welding of Aluminum Alloys
}

\author{
HongGang Yang ${ }^{1, a^{*}}$, HaiJun Yang ${ }^{2, b}$ and Xing $\mathrm{Hu}^{3, \mathrm{c}}$ \\ ${ }^{1}$ No. 1350 Ganlan road, Pudong new area, Shanghai, China \\ ${ }^{2}$ No. 1350 Ganlan road, Pudong new area, Shanghai, China \\ ${ }^{3}$ No. 1350 Ganlan road, Pudong new area, Shanghai, China \\ ayanghg@sdju.edu.cn, byanghj@sdju.edu.cn, chux@sdju.edu.cn, ${ }^{\text {’ }}$ corresponding author
}

\section{Keywords: Refill Friction Stir Spot Welding, Numerical Simulation, Material Flow}

\begin{abstract}
In order to save vehicle weight and protect environment, lightweight materials such as aluminum alloys have been widely used in the automotive industry. As a solid state jointing technique, refill friction stir spot welding (RFSSW) process is expected to apply to join automobile body parts made of aluminum sheet, because of its advantages. The present paper investigated the material flow in the plunge stage during RFSSW process by smoothed particle hydrodynamics (SPH) numerical simulation method. Material flow patterns and flow velocity was analyzed. The research results can provide guidelines for process analysis and welding quality improvement of RFSSW process.
\end{abstract}

\section{Introduction}

With the promotion of weight reduction in modern automobile industry and environment protection, aluminum alloys have been widely applied in the vehicle structure and design. Resistance spot welding (RSW) and self-piercing riveting (SPR) are the major joining process for metal sheets. However, disadvantages occur, such as large welding deformation, high energy consumption for RSW, high cost, low production efficiency for SPR, when apply these methods for aluminum alloys.

Friction stir spot welding (FSSW) is a solid state jointing process derived from friction stir welding (FSW). Compared with RSW and SPR, FSSW offers many advantages, such as low energy consumption, low heat distortion, excellent mechanical properties and a simple production procedure [1]. There are two main types of FSSW: conventional friction stir spot welding developed by Mazda in 2003[2] and refill friction stir spot welding (RFSSW) patented by GKSS in 2002[3]. Moreover, because of leaving no keyhole after welding, RFSSW technique will be widely applied in the future.

The schematic illustration of RFSSW process is shown in Fig. 1. Three parts, pin, sleeve and clamping ring are included in the RFSSW. Operated by three separate actuators, the three components of the welding tool can be rotated and moved up and down independently of each other. As shown in Fig. 1, the RFSSW process can be explained by four distinct stages: (a) the clamping ring is fixed on the top surface of the upper sheet and both the sleeve, and the pin starts to rotate and rub on the sheet for a while to soften the material so that the penetration could be more smoothly. (b) The sleeve and pin move downwards and upward, respectively, therefore the plasticized material displaced by the sleeve is squeezed into the cylindrical cavity created by the upward movement of the pin. (c) After reaching a predetermined plunge depth, both the sleeve and pin's direction of movement begin to reverse, and the plasticized material in the cylindrical cavity is squeezed back by the sleeve, hence the cylindrical cavity created by the sleeve is refilled successfully. (d) The welding head of the workpieces is removed and a flat surface connection is obtained [4]. 


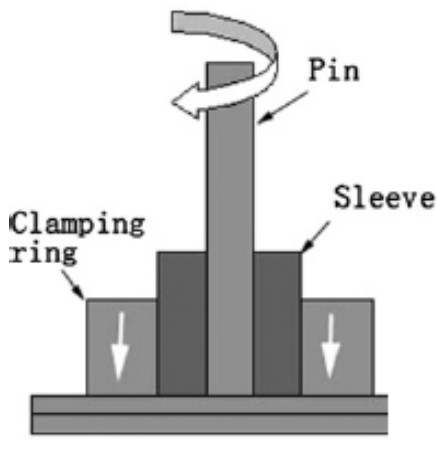

a) Stage 1

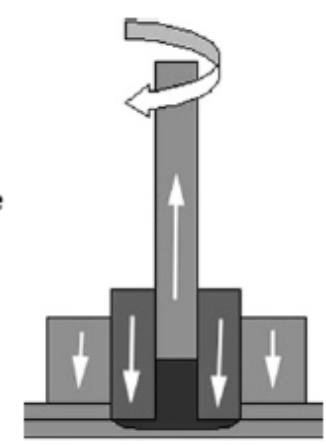

b) Stage 2

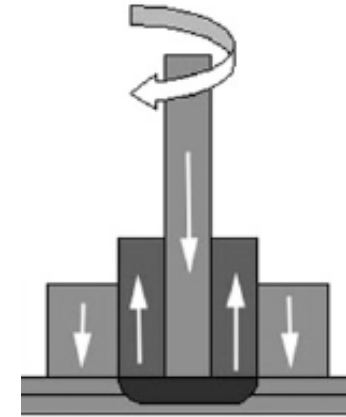

c) Stage 3

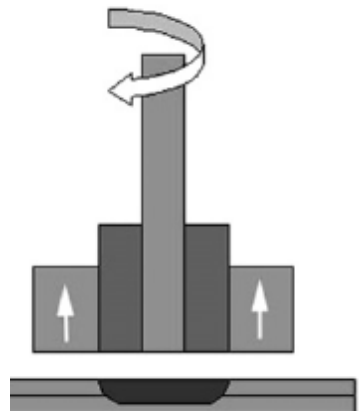

d) Stage 4

Fig.1. Schematic illustration of the RFSSW process

An understanding of material flow could provide an effective tool to improve weld strength in refill friction stir spot welding of aluminum alloys. Therefore, numerical simulation and experimental method are employed to investigate material flow during RFSSW. Muci-Kuchler et al. presented a fully coupled thermo-mechanical finite element model of the plunge phase of RFSSW, and the temperature, deformation and stress distributions are obtained [5]. Shen et al. investigated the microstructure and mechanical properties of aluminum alloys joints joined by RFSSW [6]. Microstructural features and mechanical performance of the RFSSW connections are also analyzed by Rosendo et al. in order to produce high quality joints [4]. Dongun Kim [7] performed thermo-mechanical simulations of the FSSW process to understand the effect of pin geometry on weld strength and material flow, utilizing Lagrangian and Eulerian formulations, respectively. The influence of plunge depth, rotational speed, plunge rate and time on the microstructure, material flow and shear strength was investigated by Tier [8]. The statistical software package was used to correlate process parameters with the mechanical properties of the joints.

In the present paper, the numerical simulation model of plunge stage in RFSSW of aluminum alloy was established using smoothed particle hydrodynamics (SPH) method of finite element code LS-DYNA. The material flow patterns and velocity were mainly investigated with the elastic-plastic deformation model.

\section{Basic Principles of the SPH Method}

The SPH method, which is a grid-less Lagrangian technique that originated in 1977, is a powerful feature of LS-DYNA that allows for fluidic type solutions. The main advantage of the method is to bypass the requirement for a numerical grid to calculate spatial derivatives. This avoids the severe problems associated with mesh tangling and distortion which usually occur in Lagrangian analyses involving large deformation and extreme loading events. SPH uses a kernel approximation which is based on randomly distributed interpolation points with no assumptions about which points are neighbors to calculate spatial derivatives. SPH method uses Lagrangian description, which means that particles move together with material during deformation. The time integration procedure is explicit [9].

\section{Numerical Simulation Model Description}

The numerical simulation model of plunge stage in RFSSW process has been conducted using SPH method. A 3D dynamic fully coupled analyis was performed to obtian the material flow of RFSSW process, as shown in Fig. 2. Only the work pieces were assumed to be made of deformable material, and established by SPH elements. The pin, sleeve and clamping ring were all considered as rigid using Lagrange elements, to reduce the computing time requirements. The thickness of the workpiece is $2 \mathrm{~mm}$ with $18 \mathrm{~mm}$ in diameter. The diameter of the pin, sleeve and clamping ring was chosen as 5, 9 and $18 \mathrm{~mm}$, respectively. The tool is plunged at a rate of $2 \mathrm{~mm} / \mathrm{s}$, with $2600 \mathrm{rpm}$ rotation speed. 
Aluminum alloy 6061-T6 was chosen as a material for workpieces with Young's modulus 65 GPa, and the Poisson ratio 0.3. The workpieces were modeled by $15336 \mathrm{SPH}$ nodes. The positions of the anvil and the periphery of the workpiece were fixed in the simulation. The position of the moving tool was given at each time step by curve definition. Slip at the contact surfaces between the tool and the workpiece is neglected.

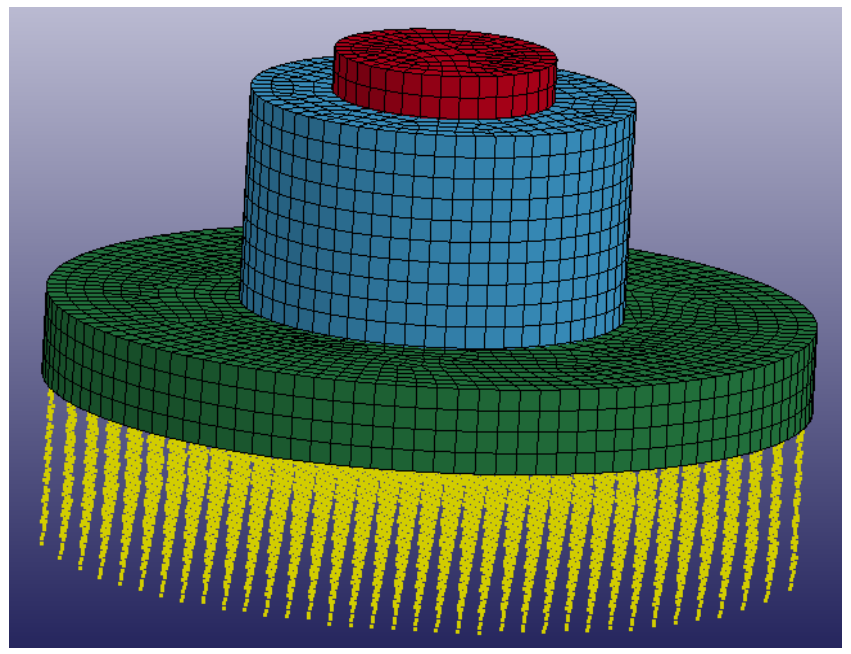

Fig. 2. Numerical simulation model of RFSSW.

\section{Results and Discussion}

Material Flow Patterns. SPH method is an effective way for material flow analysis of RFSSW process. Fig. 3 shows the numerical simulation results of the SPH nodes positions at the end of plunge stage during RFSSW in half section. With the plunge of the sleeve, the central material is squeezed into the cavity formed by the pin and the sleeve, showing upward movement. The material under the sleeve is pushed downward in the beginning, and with the increase of welding time, the material near the pin flows upward. However, close to the clamping ring periphery, the material flows downward and outward due to extrusion of the material caused by the sleeve plunge.

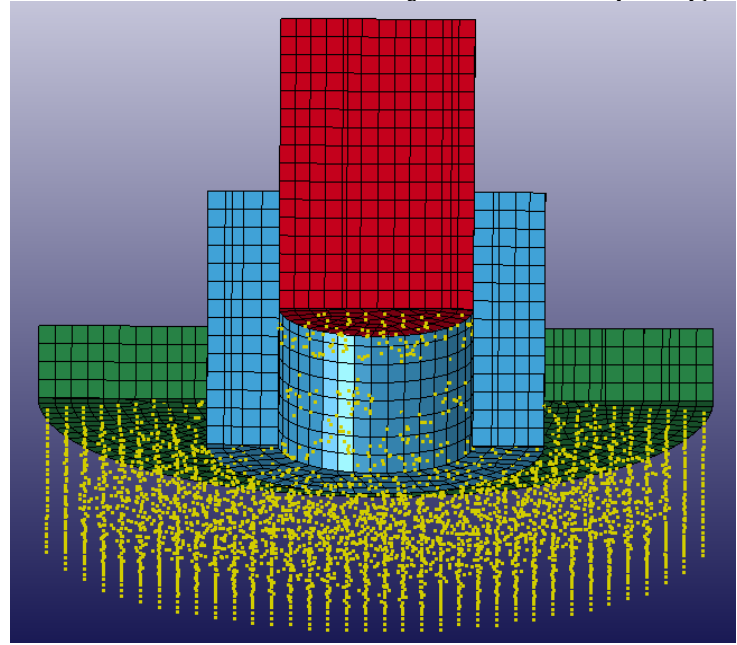

Fig. 3. Numerical simulation results of RFSSW.

Material Flow Velocity. The central material under the pin has the largest velocity, because of no constrains above. The velocity of material beneath the sleeve, especially the clamping ring, is decreased obviously. In order to ensure adequate material flow and welding quality, welding heat input should be guaranteed by increasing rotation speed and welding time.

\section{Conclusion}

RFSSW process is a solid state jointing technique, and will be widely applied in the future for aluminum alloys connections. Material flow during the plunge stage in RFSSW is investigated by 
SPH numerical simulation method, and material flow patterns and velocity is analyzed. The research results can provide guidelines for improvement of welding quality of RFSSW joints.

\section{Acknowledgment}

The authors would like to acknowledge the financial supported by Natural Science Foundation of Shanghai (Project No. 13ZR1417400) and Innovation Program of Shanghai Municipal Education Commission (Project No. 13YZ137).

\section{References}

[1] Y. S. Sato, A. Shiota, H. Kokawa, K.Okamot, Q. Yang, C. Kim, Effect of interfacial microstructure on lap shear strength of friction stir spot weld of aluminium alloy to magnesium alloy, Science and Technology of Welding and Joining, 2010 (15) 319-324.

[2] T. Iwashita, Method and Apparatus for Joining. U.S. Patent 6601751 B2. 2003.

[3] C. Schilling, and J. Dos Santos, U.S. Patent 0179 682. 2002.

[4] T. Rosendo, B. Parra, M. Tier, A. Silva, J. Santos, T. Strohaecker, Mechanical and micro structural investigation of friction spot welded AA6181-T4 aluminium alloy. Mater Des, 2011 (32) 1094.

[5] K. H. Muci-Küchler, S. Kalagara, W. J. Arbegast, Simulation of a refill friction stir spot welding process using a fully coupled thermo -mechanical FEM model, Journal of Manufacturing Science and Engineering, 2010 (132) 014503-1- 014503-5.

[6] Z. K. Shen, X. Q. Yang, Z. H. Zhang, L. Cui, T. L. Li, Microstructure and failure mechanisms of refill friction stir spot welded 7075-T6 aluminum alloy joints, Mater Des, 2013 (44) 476-486.

[7] K. Dongun, B. Harsha, R. Ill, H. K. Ji, K. Chongmin, O. Kazutaka, Numerical simulation of friction stir spot welding process for aluminum alloys, Metals and Materials International, 2010 (16) 323-332.

[8] M. D. Tier, T. S. Rosendo, J. F. dos Santos, etc. The influence of refill FSSW parameters on the microstructure and shear strength of 5042 aluminium welds, Journal of Materials Processing Technology, 2013 (213) 997-1005. 